\title{
Third International Workshop on Verification and Evaluation of Computer and Communication Systems (VECoS 2009)
}

Rabat, Morroco

2-3 July 2009

Editors:

B. Monsuez

Said El Hajji 


\section{Abstract}

The aim of VECoS workshop is to bring together researchers and practitioners in the areas of verification, control, performance, quality of service, dependability evaluation and assessment, to discuss the state of the art for solving the challenges facing us today in various modern computer and communication systems in which functional and extra-functional properties are strongly interrelated.

Thus, the main motivation for VECoS is to encourage the cross-fertilization between formal verification and evaluation approaches, methods and techniques especially those based on the specification formalisms for concurrent, distributed and soft/hard systems. Beyond its technical and scientific goals, another main purpose of VECoS is to promote collaboration between participants in research and education in the area of computer science and engineering.

This conference is sponsored by:
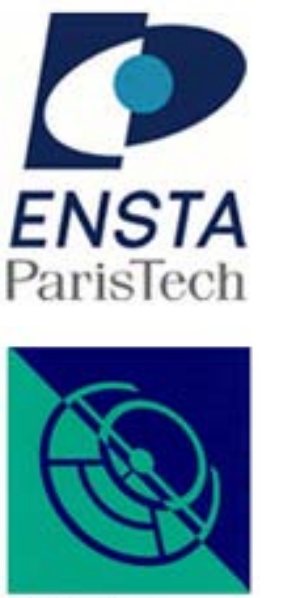

Minist ère de

I'enseignement supérieur

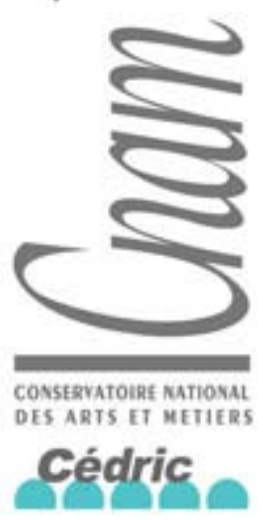

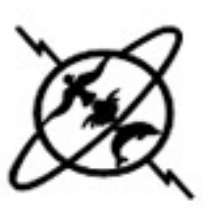

Faculté des sciences

de Rabat

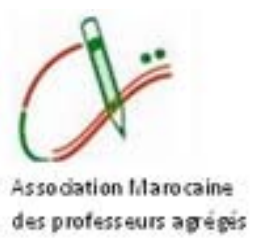

Maroc

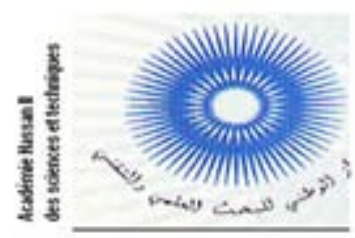

Telecom

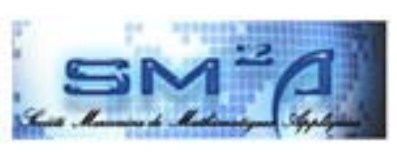




\section{Full Synopsis}

The International Workshop on Verification and Evaluation of Computer and Communication Systems (VECoS) is one of the leading forums for the presentation of all aspects of verification, performance modeling and analysis of computer and communication systems.

VECOS offers a unique forum for researchers and practitioners from academia to share their expertise results and achievements in all areas of verification and performance evaluation of computer and communication systems including analytic modeling, simulation and measurements.

The first edition was held in Algiers, Algeria (2007), the second edition was held in Leeds, Great Britain (2008). This year's edition is held in Rabat, Morocco.

This year's programme consists of four regular paper sessions and four invited talks. Various topics are covered in the programme and include Petri nets, model checking, formal verification, embedded systems and wireless networks.

These proceedings record the contributions from the technical sessions. We present thirteen technical papers selected out from twenty-four submissions.

We have been delighted by the overwhelming response from the international community of computer and communication systems to our call for papers. The workshop attracted a large number of high quality papers from many countries. Once again we welcome back our colleagues from Tunisia, Morocco, Algeria, France, Germany, Italy, Canada, and the United Kingdom.

The programme committee includes researchers from forty-three laboratories. Each paper submitted was evaluated by at least three reviewers. After the evaluation, reports were returned to the programme committee for discussion and resolution of conflicts. Based on their recommendations, we implemented a consensus process, and selected the thirteen papers that we present here.

We are grateful to all members of the programme committee, the organising committee and to all referees for their hard work. The support and encouragement of the steering committee were invaluable assets. Without the support of our institutions, VECoS2009 could not have been a reality. Their recognition of the importance of this event is greatly appreciated. Finally, we would like to thank all the authors of the invited and submitted papers, and all participants at the Workshop. They are the main focus of VECoS.

We would also like to thank the University of Mohammed V-Agdal for hosting the event.

Bruno Monsuez and Said El Hajji

VECoS'2009 Co-Chairs

Rabat, July 2008 


\section{Editors}

This conference was edited by:

B. Monsuez - ENSTA PARIS, France, Email: Bruno.Monsuez@ensta.fr

Said El Hajji - University of Mohammed V - Agdal, Rabat, Morocco, Email: elhajii@fsr.ac.ma

\section{Steering Committee}

Hassane Alla LAG-INPG Grenoble, France

Nadjib Badache LSI-USTHB Algiers, Algeria

Kamel Barkaoui (Chair) CEDRIC-CNAM Paris, France

Rahma Ben Ayed SysCom-ENIT Tunis, Tunisia

Karim Djemame University of Leeds, UK

Karim Djouani LISSI Universite Paris 12 Creteil, France

Mohamed Kaaniche LAAS CNRS Toulouse, France

Bruno Monsuez Ensta, PARIS, France

Patrice Moreaux LISTIC University of Savoie Annecy, France

\section{Programme Committee}

Anas Abou El Kalam, IRIT-INT ENSEEIHT, Toulouse, France

Johnson I Agbinya, F'SATIE / Alcatel Centre for Content Development, Pretoria, South Africa

Djamil Aissani, LAMOS, Abderrahmane Mira University, Béjaïa, Algeria

Yamine Ait Ameur, LISI/ENSMA, Poitiers, France

Nasreddine Aoumeur, Otto-von-Guericke-University Magdeburg, Germany 
Souheib Baarir, ALSOC, Pierre \& Marie-Curie University, Paris, France

Faiza Belala, Mentouri University, Constantine, Algeria

Abdelfettah Belghith, ENSI Tunis, Tunisia

Saddek Bensalem, VERIMAG, Joseph Fourier University, Grenoble, France

Béatrice Bérard, LIP6/MoVe, Pierre \& Marie-Curie University, Paris, France

Elmarie Bierman, Faculty of ICT, Tshwane University of Technology, Pretoria, South Africa

Maria Blanca Caminero Herraez, Universidad of Castilla-La Mancha, Spain

Boutheina Chetali, Security Labs, Technology \& Innovation, Gemalto, Meudon, France

Jean-Michel Couvreur, LIFO, University of Orléans, France

Abdelouahid Derhab, Cerist, Algiers, Algeria

Djamel Djenouri, IET NTNU, Throndheim, Norway

Said El Hajji, Faculty of Science at University of Mohammed V - Agdal, Rabat, Morocco (Co-Chair)

Mohammed Erradi, ENSIAS, University of Rabat, Morroco

Joaquin Ezpeleta, C.P.S. University of Zaragoza, Spain

Pascal Fontaine, LORIA, University of Nancy 2, France

Malika Ioualalen, USTHB, Algiers, Algeria

Mohamed Jmaiel, ENIS, Sfax, Tunisia

Moez Krichen, VERIMAG, University Joseph Fourier, Grenoble, France

Jean-Jacques Lesage, LURPA, ENS Cachan, France

Ka Lok Man, CEOL, University of Cork, Ireland

Mourad Maouche, Philadelphia University, Jordan

Micaela Mayero, LIPN, University of Paris-Nord, France

Mohamed Mezghiche, LIFAB, University of Boumerdes, Algeria

Noufissa Mikou, LIRSA, University of Bourgogne, Dijon, France

Bruno Monsuez, ENSTA, France (Co-Chair)

Otmane Ait Mohamed, Concordia University, Canada

Mohamed Mosbah, LaBRI Bordeaux, France

Hassan Mountassir, LIFC University Franche-Comte, France 
Mohamed Ould-Khaoua, University of Glasgow, UK

Nihal Pekergin, LACL, University Paris East, France

Franck Pommereau, LACL, University Paris East, France

Omer F. Rana, Cardiff University, UK

Eric Rutten, POP-ART, INRIA Rhônes Alpes, France

El Mamoun Souidi, Faculty of Science atUniversity Mohammed V - Agdal, Rabat, Morocco

Samir Tata, INT, Evry, France

Tayssir Touili, LIAFA, University Paris-Diderot, France

Franck Védrine, CEA LIST, Saclay, France

Moez Yeddes, ENSI Tunis, Tunisia

Habib Youssef, HICST, Hammam Sousse, Tunisia

\section{Local Arrangements}

E. M. Souidi University of Mohammed V - Agdal, Rabat, Morocco

J. Laassiri University of Mohammed V - Agdal, Rabat, Morocco

M. Benaini University of Mohammed V - Agdal, Rabat, Morocco

M. Bouhdadi University of Mohammed V - Agdal, Rabat, Morocco

M. Rziza University of Mohammed V - Agdal, Rabat, Morocco

M. Zbakh University of Mohammed V - Agdal, Rabat, Morocco

O. El Imrani University of Mohammed V - Agdal, Rabat, Morocco

S. El Bernoussi University of Mohammed V - Agdal, Rabat, Morocco

S. El Hajji University of Mohammed V - Agdal, Rabat, Morocco

M. Chabbar University of Mohammed V - Agdal, Rabat, Morocco

A. El Ghazi University of Mohammed V - Agdal, Rabat, Morocco

N. Zahid University of Mohammed V - Agdal, Rabat, Morocco

M.Jedra University of Mohammed V - Agdal, Rabat, Morocco 


\section{Papers:}

\section{Session 1: Wireless Networks}

Sabrina Abid and Pr. Hafid Haffaf Optimal Sensors Placement for Failures Detection and Isolation http://dx.doi.org/10.14236/ewic/VECOS2009.1

Said El Hajji and Ghizlane Orhanou Confidentiality in the UMTS Radio Access Network Simulation approach under OPNEThttp://dx.doi.org/10.14236/ewic/VECOS2009.2

Fouzi Semchedine, Louiza Bouallouche-Medjkoune, Sofiane Moad, Rafik Makhloufi and Djamil Aïssani Discrete Events Simulator for wireless sensor networks http://dx.doi.org/10.14236/ewic/VECOS2009.3

Jun Chen, Karim Djouani and Kamel Barkaoui Orthogonal and Non-orthogonal Cooperative protocols in WLANs http://dx.doi.org/10.14236/ewic/VECOS2009.4

\section{Session 2: Timed Systems \& Model Checking}

Florent Peres, Pierre-Emmanuel Hladik and François Vernadat Specification and Verification of RealTime Systems using the POLA tool http://dx.doi.org/10.14236/ewic/VECOS2009.5

M.C. Boukala and L. Petrucci Distributed CTL Model-Checking and counterexample search http://dx.doi.org/10.14236/ewic/VECOS2009.6

Nesrine Harrath and Bruno Monsuez Timed SystemC Waiting-State Automata http://dx.doi.org/10.14236/ewic/VECOS2009.7

\section{Session 3: Control \& Dependability}

Martin Oberkönig, Martin Schickel and Hans Eveking Improving Testbench Evaluation using Normalized Formal Properties http://dx.doi.org/10.14236/ewic/VECOS2009.8

O. Malassé, G. Buchheit, K. Hamidi, M. Pock, H. Belhadaoui, M. Walter and J.F. Aubry Dependability Evaluation of Complex Embedded Systems and Microsystems http://dx.doi.org/10.14236/ewic/VECOS2009.9 
Abbas Dideban and Hassane Alla Controller Synthesis by Petri Nets Modelling http://dx.doi.org/10.14236/ewic/VECOS2009.10

\title{
Session 4: Model \& System Design
}

\author{
Ahmed Mekki, Mohammed Ghazel and Armand Toguyeni Validating time-constrained systems \\ using UML Statecharts Patterns and Timed Automata Observers \\ http://dx.doi.org/10.14236/ewic/VECOS2009.11
}

Linda Mohand Oussaïd, Yasmine Aït Ameur and Mohammed Ahmed Nacer

A generic formal model for fission of modalities in output multi-modal interactive systems

http://dx.doi.org/10.14236/ewic/VECOS2009.12 